\title{
Sem tecto entre ruínas...
}

\section{Maria Helena Serôdio}

Ao entrarmos no décimo ano da publicação - regularissima - desta nossa revista, tomei de empréstimo a Augusto Abelaira o título do seu romance de 1979, mas reconduzindo-o a uma mais actual e alargada incidência temporal. Porque este é, a meu ver, o motto que me parece mais condizente com a injusta situação que, ultimamente, tem sido imposta - em Portugal - à cultura e à arte, desta forma reduzindo-Ihe o seu campo de actuação e a força da sua intervenção social. 0 que não significa que não seja igualmente visivel, por parte da comunidade artística, uma vontade de não desistir, obstinando-se, pelo contrário, na reconfirmação da sua criatividade. É é isso que nos vai permitindo uma sempre renovada configuração do nosso imaginário, aquela instância que nos acrescenta vida e nos permite ainda o sonho e a vontade de instaurar um outro mundo no mundo que nos rodeia.

o Prémio da Crítica relativo a 2012 veio também provar a verdade desta afirmação. Distinguiu este ano o encenador Rogério de Carvalho que se tem revelado de uma excepcional sensibilidade na criação de imagens cénicas e na direcção de actores, personificando o exemplo maior de uma rara combinação de rigor e de sensibilidade, criando partituras exemplares de forte visualidade (com um inspirado trabalho de luzes), sem descurar a atenção à proferição da palavra e às sonoridades em cena.

As outras distinções, que a APCT atribuiu, sublinharam outras valências, mas não menor excelência. É o caso de João Tuna, o fotógrafo mágico que, com a sua objectiva, vem criando verdadeiras obras de arte, acrescentando valor, alento e posteridade às imagens de cena que capta. 0 coffret belissimo que o Teatro Nacional São João editou este ano - Todos os fantasmas usam botas pretas, Rastros: TNSJ 1996 - 2009 (TNSJ, 2012) - assenta na magia das fotografias que João Tuna soube criar, repartindo a sua obra em quatro tempos/livros, e a cada um atribuindo um lugar dramatúrgico: Rastros, Geometrias, Vapores, Figurantes. Reserva ainda, no "esconso" do cofre, um pequeno livro, de capa igualmente vermelha (encastrado na caixa maior), com a lista dos espectáculos produzidos pelo TNSJ nesse intervalo de tempo, ao lado de curtos textos de Ricardo Pais, Manuel Maria Carrilho, João Luis Pereira, Pedro Sobrado e John Havelda, para além da breve nota biográfica de João Tuna. Nela se esclarece o que em João Tuna excede o gesto fotográfico para incluir a escrita de peças, a realização de curtas-metragens, os registos fílmicos de alguns espectáculos (e sabemos como são magníficos), e um vídeo de dança. Só não acrescenta o que para nós, na revista, tem sido o seu traço humano mais constante: a sua insuperável generosidade, que se agiganta sempre no apoio continuado à ilustração desta nossa Sinais de cena.

Peça invulgar na história de um teatro em Portugal, este livro raro - "dedicado" à arte maior de João Tuna regista, no pequeno livro de capa vermelha, com inteira justiça, o nome de alguém que foi testemunha atenta e colaborador brilhante do TNSJ durante esse período: Paulo Eduardo Carvalho. E este nome e esta lembrança viva continuam a ser para nós uma fonte de inspiração permanente que se reacende em cada momento que recomeçamos o trabalho de edição da Sinais de cena: em grande parte, é para ele que continuamos a escrever!

Foi ainda distinguido pela APCT o deslumbrante espectáculo Os juramentos indiscretos, sobre texto de Marivaux, que José Peixoto encenou com o Teatro dos Aloés, e que brilhou pelas várias artes que convocou em cena, como escreveu João Carneiro: uma tradução exemplar (de Maria João Brilhante), um trabalho de actores refinado e inteligente, um dispositivo cenográfico (de Marta Carreiras) adequado aos propósitos da peça e da encenação. Tudo numa especial conflagração de sentidos e valores artísticos que José Peixoto soube orquestrar de forma admirável.

Destacou ainda o júri da APCT o espectáculo Salomé, encenado por Bruno Bravo com a sua companhia Primeiros 
Teresa da Palma Pereira,

2013

fot. Joana d'Eça Leal

Rui Pina Coelho

Maria Helena Serôdio, Alexandra Moreira da Silva (Júri) e João Tuna,

2013

fot. Eunice Tudela

de Azevedo

Bruno Bravo, 2013

fot. Eunice Tudela

de Azevedo.
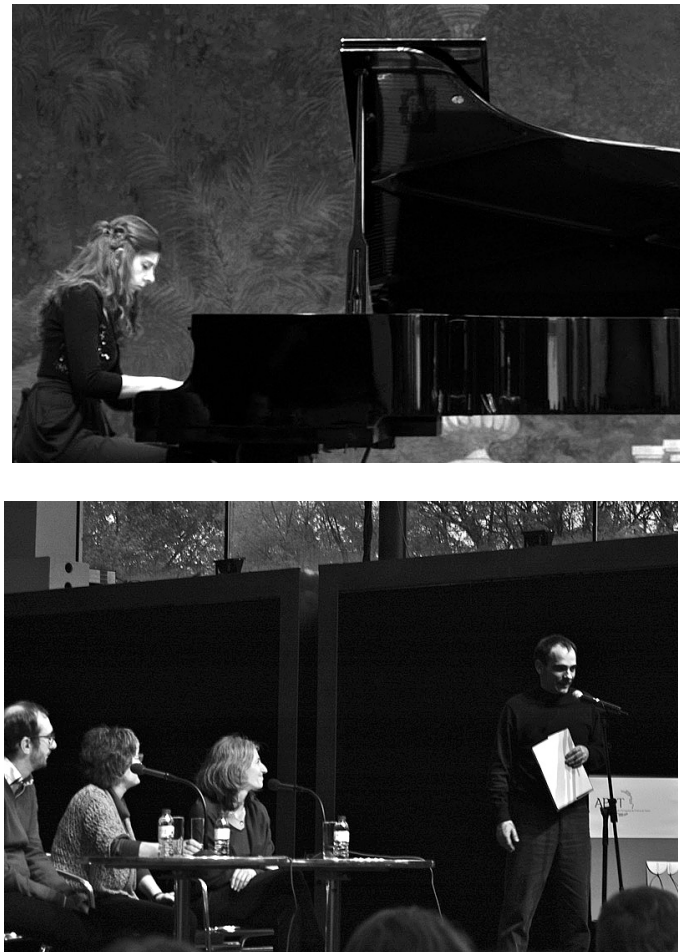

3

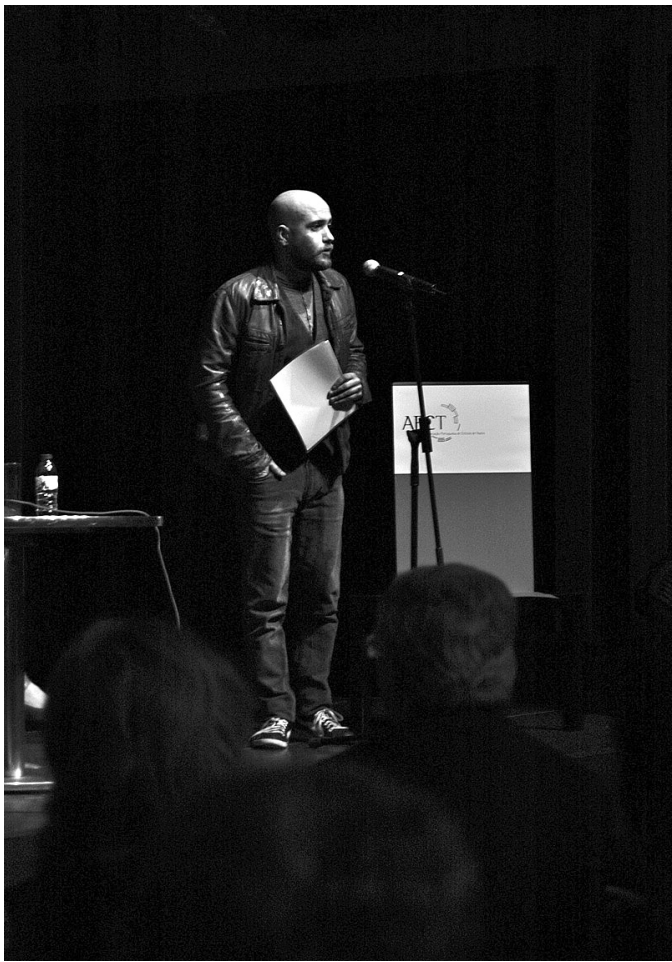

E.

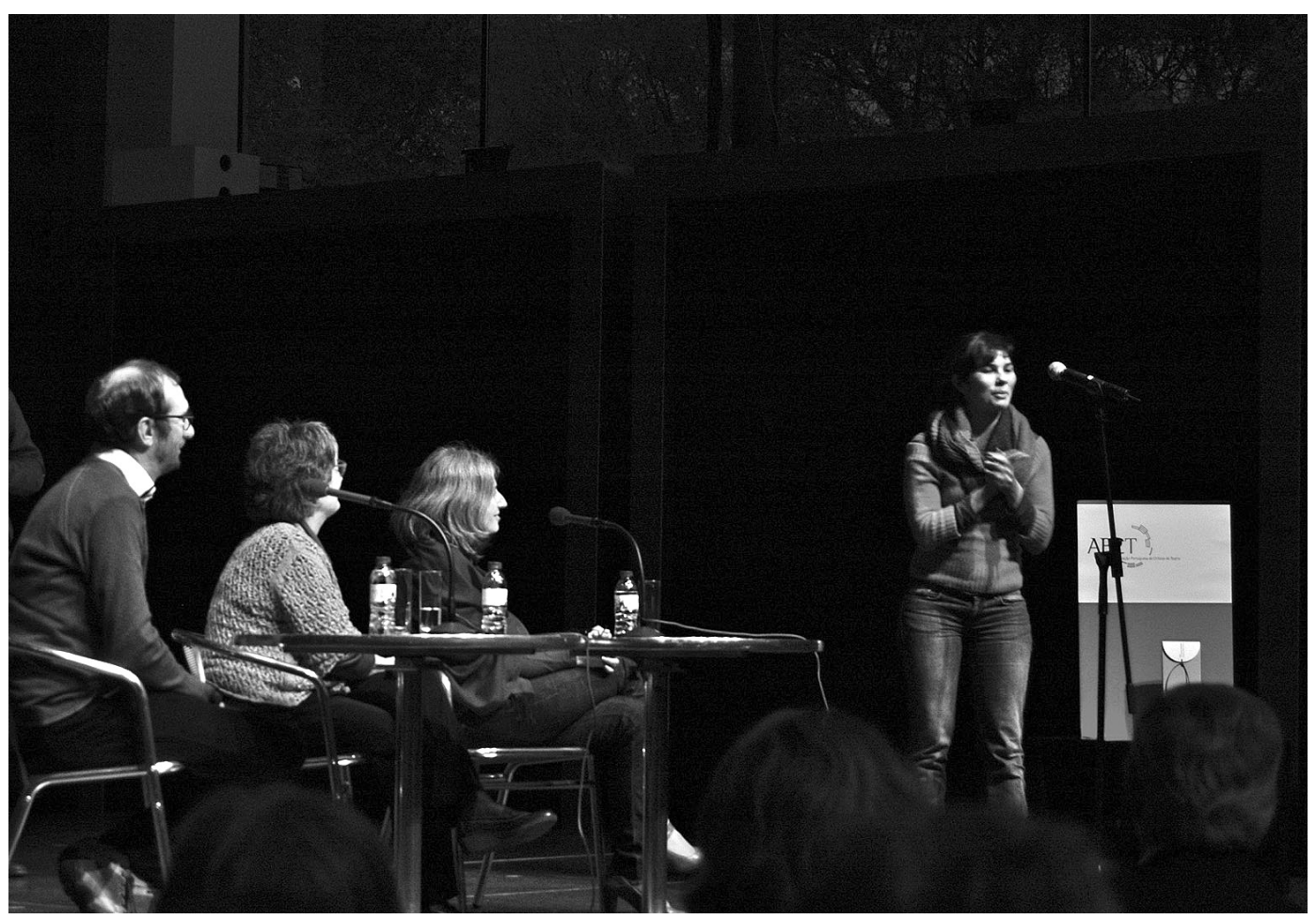

Sintomas, sublinhando o que nele foi um espectáculo de poesia, que ousou subverter a interpretação das regras dramáticas, criando assim, nas palavras de Rui Monteiro, um território fantasmático, para o que muito contribuiu a tradução do texto de Oscar Wilde por Aníbal Fernandes a cenografia (de Stéphane Alberto), a luz (de João Paiva), o trabalho dos actores, enfim, tudo o que, ao longo do espectáculo, conduzia o público por uma "expedição a um lugar sonhado - à maneira de parque de diversões - de frustração da carne e da decadência do espírito".

A sessão da atribuição do Prémio, realizada mais uma vez no encantador Jardim de Inverno do São Luiz Teatro
Municipal, por cedência generosa do seu Director José Luis Ferreira e ajuda preciosa de Aida Tavares, foi um momento de grande emoção e amabilíssimo convívio, em que pudemos contar também com a participação da jovem pianista Teresa da Palma Pereira que, no início da sessão interpretou, de forma brilhante, a Fantasia em Dó Maior Wanderer, de Franz Schubert.

Entretanto, o conteúdo deste número da Sinais de cena cumpre, uma vez mais, escrupulosamente, as dez rubricas que consideramos ser as modalidades várias de documentar, interpelar, criticar e historiar as artes cénicas. Assim no "Arquivo solto", Luís Gameiro recorda a pedagogia 


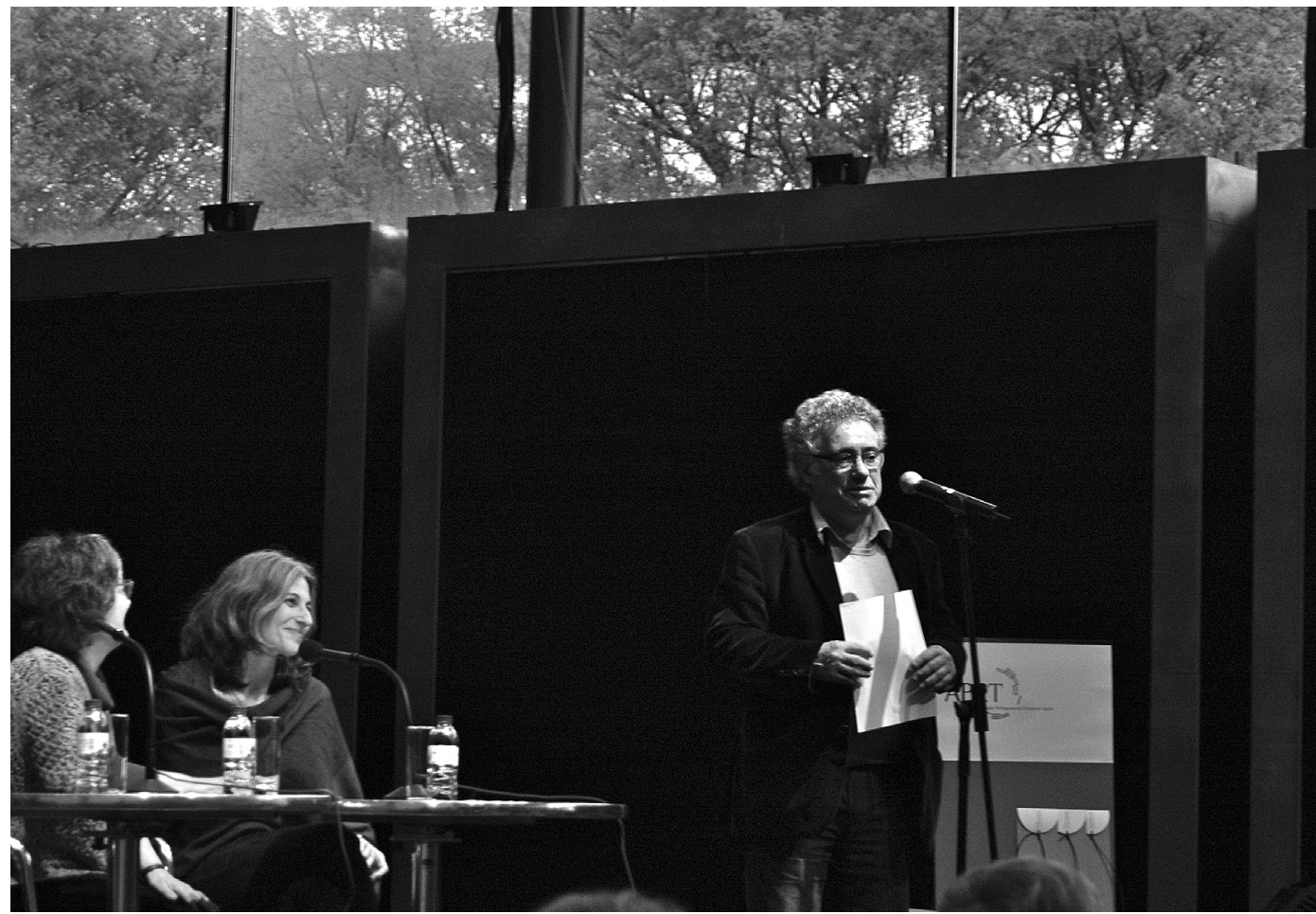

teatral de António Pinheiro (1867-1943) com base na rigorosa investigação que realizou para a sua dissertação de Mestrado (apresentada à Faculdade de Letras da Universidade de Lisboa), enquanto no "Dossiê temático" se registam as razões que o júri do Prémio da Crítica invocou para justificar as distinções atribuidas (como ocorre desde o seu primeiro número, sempre na edição do mês de Junho).

Nas rubricas "Portefólio" e "Na primeira pessoa" surgem, neste número, em retratos de forma diversa, mas de idêntico valor na revelação da sua inventividade, duas criadoras, que, apesar de jovens, contam já com um trajecto artístico de reconhecido valor: Patricia Portela e Joana Craveiro, respectivamente. Cada uma revela pela escrita em diálogo - com Ana Pais e Eunice Tudela de Azevedo, respectivamente - o seu percurso singular nas artes cénicas em Portugal pela invenção de mundos seus muito próprios de que aqui damos testemunho breve, mas eloquente.

Nas "Noticias de fora" chegam-nos apreciações de um Festival de Teatro no Brasil (pela escrita de Jorge Louraço Figueira) e de formas inovadoras na relação entre o teatro e a crítica na Itália (na visão de Sergio Lo Gatto), enquanto que, na secção "Em rede", Ana Campos nos conduz por uma viagem pelo sítio electrónico dos Rimini Protokoll, partilhando connosco o reconhecimento pelos modos inusuais de fazer teatro em que se empenha a companhia que Stefan Kaegi dirige.

A secção dos "Estudos aplicados" é, neste número, a que recolhe um maior número de contribuições, embora de orientação ensaística bem diversa: Glória Bastos inventaria e avalia perspectivas actuais do teatro para crianças; Filipe Figueiredo interroga a condição da fotografia de teatro; Christine Zurbach estuda a tradução de teatro que Luiz Francisco Rebello praticou; Arthur E.A. Belloni elabora um argumento em torno do artifício da cena contemporânea; e Sílvia Laureano Costa analisa o percurso do texto de Almada Negreiros - Deseja-se mulher - desde a sua escrita até à passagem pelo exame de censura prévia e à sua recriação cénica por Fernando Amado, em 1963, na Casa da Comédia.

A análise de espectáculos, que nos oferece a secção "Passos em volta", relembra, nas palavras de Emilia Costa, Por tudo e por nada, de Nathalie Sarraute, pelos Artistas Unidos, Gaspar, pel'A Turma (em ligação a Guimarães) nas palavras de Ricardo Fonseca, Nióbio, das Visões Úteis, por Jorge Palinhos, enquanto Constança Carvalho Homem nos traz notícia crítica sobre Raso como o chão dos Três Quatro Lente, e Sebastiana Fadda nos ensina a importância de Goldoni e da sua arte maior na História do Teatro e da parte para uma análise do espectáculo A estalajadeira que Jorge Silva Melo encenou com os Artistas Unidos.

Na secção "Leituras", ainda Sebastiana Fadda uma vez mais - com a sua inexcedivel competência e rigor organiza a lista dos livros de e sobre teatro que se publicaram no ano anterior à saída do número de Junho da revista, pelo que neste caso se reporta a 2012. Mas cabem ainda nesta secção uma recensão por Rui Pina Coelho de Do precipicio tempestuoso de Ricardo III, de Luis Mestre, uma referência à publicação do Teatro de Alves Redol, que Miguel Falcão organizou para a Imprensa Nacional - Casa da Moeda bem como o seu estudo sobre a obra redoliana, por MHS, e curtas apreciações críticas, por Ana Campos, de uma colecção de livros dados à estampa em Évora sobre dramaturgia e que inclui autores como Anne Ubersfeld, Jean-Pierre Sarrazac, Joseph Danan, e, como organizadoras, Christine Zurbach e Célia Caravela.

Na breve apresentação do que é este número não posso deixar de registar os nossos mais vivos agradecimentos às três instituições que generosamente aceitaram publicitar as suas actividades neste número, viabilizando, assim, a sua edição: o Teatro Nacional São João, o Teatro Nacional D. Maria II e a Sociedade Portuguesa de Autores. São para nós companheiros inestimáveis nesta longa - mas indispensável - caminhada pelo teatro que se vai fazendo, apesar de todas as dificuldades que continuamente se vêm abatendo sobre todos nós! 


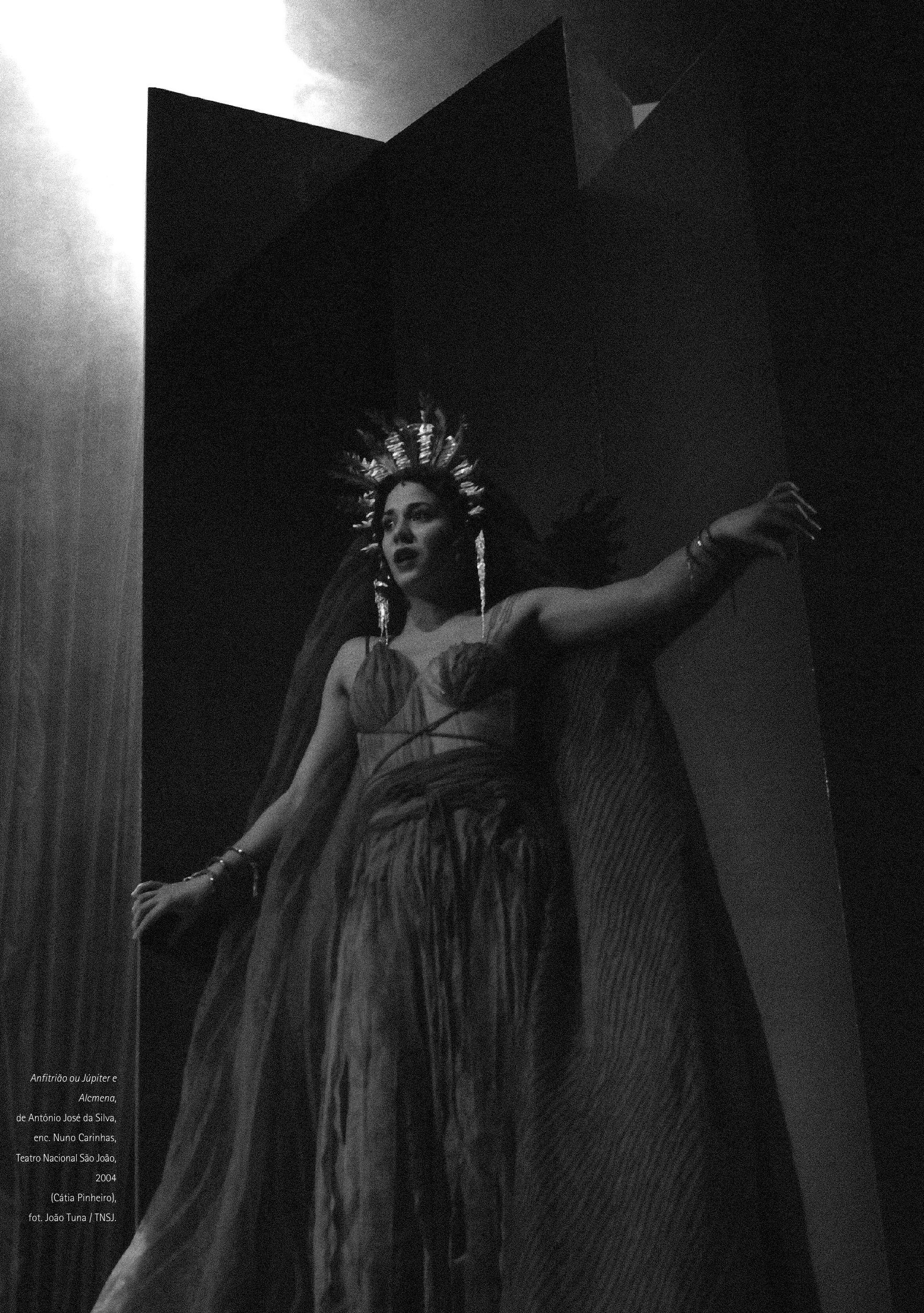

